OPEN ACCESS

Edited by:

Roumen Kirov,

Institute of Neurobiology (BAS),

Bulgaria

Reviewed by:

Jana Strahler,

Justus-Liebig-Universität Gießen,

Germany

Axel Steiger,

Max-Planck-Institut für Psychiatrie,

Germany

Ines Pfeffer,

Medical School Hamburg, Germany

*Correspondence:

Markus Gerber

markus.gerber@unibas.ch

Specialty section:

This article was submitted to

Psychopathology,

a section of the journa

Frontiers in Psychology

Received: 14 August 2018 Accepted: 11 October 2018 Published: 02 November 2018

Citation:

Gerber M, Isoard-Gautheur S, Schilling R, Ludyga S, Brand S and

Colledge $F$ (2018) When Low Leisure-Time Physical Activity Meets Unsatisfied Psychological Needs:

Insights From a Stress-Buffer

Perspective. Front. Psychol. 9:2097.

doi: 10.3389/fpsyg.2018.02097

\section{When Low Leisure-Time Physical Activity Meets Unsatisfied Psychological Needs: Insights From a Stress-Buffer Perspective}

\author{
Markus Gerber ${ }^{1 *}$, Sandrine Isoard-Gautheur ${ }^{2}$, René Schilling ${ }^{1}$, Sebastian Ludyga ${ }^{1}$, \\ Serge Brand ${ }^{1,3,4}$ and Flora Colledge ${ }^{1}$
}

${ }^{1}$ Department of Sport, Exercise and Health, Sport Science Section, University of Basel, Basel, Switzerland, ${ }^{2}$ Laboratoire Sport et Environnement Social, Université Grenoble Alpes, Grenoble, France, ${ }^{3}$ Center for Affective, Stress and Sleep Disorders, University of Basel, Basel, Switzerland, ${ }^{4}$ Substance Abuse Prevention and Sleep Disorders Research Center, Kermanshah University of Medical Sciences, Kermanshah, Iran

Background: Few studies have tested whether the stress-buffering effects of leisuretime physical activity (LTPA) depend on other resources, such as the satisfaction of basic psychological needs. Therefore, the present study examines the interaction between perceived stress, LTPA and psychological need satisfaction (PNS) on occupational burnout symptoms in a sample of Swiss workers.

Methods: The sample consisted of 306 employees (48\% women; $M_{\text {age }}=42.9$ years, $S D=14.1)$. Perceived stress was assessed with the Perceived Stress Scale, LTPA with the International Physical Activity Questionnaire, PNS (autonomy, relatedness, and competence) with the Need Satisfaction Scale, and occupational burnout symptoms with the Shirom-Melamed Burnout Measure. A hierarchical regression analysis and single slopes tests were performed to examine two- and three-way interactions.

Results: Stress was positively correlated with burnout, and negatively correlated with LTPA and PNS levels. LTPA was positively associated with PNS, and negatively correlated with burnout. A negative association existed between PNS and burnout. In the hierarchical regression analysis, all main effects, two- and three-way interactions were significant. People who engaged in more LTPA reported fewer burnout symptoms, if they reported high stress. However, the potential of LTPA to buffer stress was particularly evident in participants who reported low PNS.

Conclusion: If adult workers are exposed to elevated stress, they are particularly likely to show increased burnout levels if they report low LTPA in combination with low PNS, specifically a lack of autonomy, competence and relatedness.

Keywords: autonomy, burnout, competence, relatedness, self-determination theory, stress

\section{INTRODUCTION}

Chronically high perceived stress constitutes a heavy burden on individuals' health, by increasing their risk for non-communicable diseases (Bergmann et al., 2014), jeopardizing their mental health (Siegrist, 2008), and ultimately leading to premature death (Redmond et al., 2013). Furthermore, it is one of the key factors in the development and persistence of occupational 
burnout (Glise et al., 2010). Previous research has shown that both leisure-time physical activity (LTPA) and the satisfaction of basic psychological needs are important health resources (Deci and Ryan, 2000; Biddle and Mutrie, 2006) which may facilitate successful coping with stress. Given these insights, the purpose of the present study was to examine, in a sample of Swiss adult workers, whether a combination of low LTPA and unsatisfied psychological needs is associated with increased burnout symptoms among participants who perceive their lives as being stressful, as compared to individuals who report low stress levels. This study addresses an important void in the literature, since little is known so far about whether the potential of LTPA to buffer stress is modulated by other personal and/or social factors.

In the present study, a special focus is placed on occupational burnout symptoms, because they have been considered as a major indicator of impaired well-being in working populations (Schaufeli and Bakker, 2004). Taking into consideration the basic tenets of the Conservation of Resources (COR) theory (Hobfoll and Shirom, 2000), Shirom et al. (2006) defined burnout as an individual's feeling of being emotionally exhausted, physically fatigued, and cognitively worn-out. Using this definition of burnout, research has shown that burnout is associated with both physiological and psychological health outcomes. On the physiological side, higher burnout scores are related to increased cardiovascular risk factors such as increased fasting glucose, total cholesterol, low-density lipoprotein cholesterol and triglyceride levels (Gerber et al., 2016), increased cortisol levels throughout the day (Melamed et al., 1999), an elevated cortisol awakening response (Grossi et al., 2005), increased inflammation markers (Toker et al., 2005), and increased risk of developing type 2 diabetes (Melamed et al., 2006). As regards psychological dimensions, significant relationships exist between higher burnout symptoms, reduced life satisfaction and quality of sleep (Gerber et al., 2015), and depressive symptoms, with varying degrees of overlap (Schonfeld and Bianchi, 2016).

The relationship between LTPA and burnout symptoms is a relatively new area of scientific enquiry, because researchers have predominantly focused on depression as a mental health outcome (Mead et al., 2009). Nevertheless, evidence has increased during recent years, showing that a significant association exists between LTPA and burnout symptoms (Wunsch and Gerber, 2017). In a prospective study, Jonsdottir et al. (2010) showed that low LTPA predicted increased burnout symptoms over a 2-year period. In a cross-sectional study, Lindwall et al. (2012) found that lower self-reported LTPA levels were more closely associated with people's burnout symptoms than objectively assessed cardiorespiratory fitness. Moreover, using latent growth curve analyses, Lindwall et al. (2014) showed in a longitudinal study that decreases in LTPA over a 4-year period are paralleled by an increase in burnout symptoms, and vice versa. In two cross-sectional investigations, Elliot et al. (2015) and Gerber et al. (2015) showed that vocational students who attain recommended levels of LTPA (according to internationally accepted standards) experience fewer burnout symptoms compared to peers with insufficient LTPA levels. Moreover, most of the existing experimental or quasi-experimental studies indicate that LTPA or exercise training leads to a reduction of burnout symptoms
(Tsai et al., 2013; Bretland and Thorsteinsson, 2015; de Vries et al., 2017). From a stress-buffer perspective and based on crosssectional data, Gerber et al. (2013b) reported a significant twoway interaction between self-reported stress and participants' cardiorespiratory fitness levels. This indicates that the association between cardiorespiratory fitness and burnout symptoms is particularly strong in individuals who perceive high stress. Based on their findings, Gerber et al. (2013b) concluded that beyond primary prevention efforts to create less stressful work environments, promoting more active lifestyles could be a target for occupational health managers, because regular LTPA can strengthen employees' capacity to cope with stress and stressrelated disorders.

In summary, it appears that regular LTPA decreases the risk of developing burnout symptoms and can provide some protection against stressful life circumstances. However, the available research insufficiently accounts for the fact that other personal and social influences may serve as vulnerability factors or resilience resources (Luthar et al., 2006). In the present study, satisfaction with basic psychological needs is addressed for two reasons. First, previous research has indicated that personal factors might impact the ability of LTPA to buffer stress. For instance, focusing on the construct of hardiness, Kobasa et al. (1982) showed in a cross-sectional study that when exposed to high stress, participants with high hardiness and exercise scores remained more healthy than those with high scores in only one of these constructs. Similar findings were reported by Kobasa et al. (1985) in a prospective study showing that the total number of resistance resources (exercise, hardiness, and social support) predicted illness symptoms among participants exposed to high stress levels. Second, grounded in the self-determination framework (Deci and Ryan, 2000), previous investigations have pointed out that psychological need satisfaction (PNS) is positively associated with people's well-being and contributes to their ability to deal with stress (Reis et al., 2000).

Self-determination theory (SDT) is an organismic metatheory on human motivation and personality (Ryan and Deci, 2000; Deci and Ryan, 2002). Within this framework, the Basic Psychological Need Theory (BPNT) constitutes a mini-theory, which has become a popular approach to understanding how stressful life circumstances can lead to decreased performance and impaired well-being (Quested et al., 2011; Gunnell et al., 2013). A central tenet of BPNT is that satisfaction of basic psychological needs not only promotes human motivation and personality development, but is also key for well-being and the prevention of psychopathological symptoms. In this theory, Deci and Ryan (2000) define basic psychological needs as "those nutriments that must be procured by a living entity to maintain its growth, integrity and health" (p. 326). According to Van den Broeck et al. (2008), PNS is essential for humans to actualize their potential, to flourish, and to be protected from ill health and maladaptive functioning. There are three psychological needs in question, namely autonomy (e.g., having a choice and being able to determine one's own actions), competence (e.g., feeling effective in interacting with one's environment, feeling able to apply or develop one's skills and capacities and to accomplish 
desired goals), and relatedness (e.g., feeling of mutual respect and having close relationships with other people, feeling love and care by significant others) (Vansteenkiste and Ryan, 2013). As mentioned above, prior studies support the notion that PNS is positively associated with psychological functioning across different life domains (Milayavskaya and Koestner, 2011). In the context of work, high PNS was found to be related to participants' well-being (Lynch et al., 2005), job satisfaction (Ilardi et al., 1993), motivation (Gagné, 2003), dedication (Vansteenkiste et al., 2007), and performance (Baard et al., 2004), whereas low PNS was related to occupational burnout, both on an interpersonal (Vansteenkiste et al., 2007) and intrapersonal level (Aldrup et al., 2017). Furthermore, cross-sectional (Van den Broeck et al., 2008) and longitudinal evidence (Aldrup et al., 2017) suggests that PNS may function as a mediator between workrelated stress and burnout symptoms. These studies indicate that stress may negatively affect PNS, which in turn may increase the risk of developing burnout symptoms. By contrasts, we are not aware of any previous studies in which PNS was conceptualized as a moderator, although such an approach accords well with a resilience perspective. As highlighted by Luthar et al. (2006), resilience researchers are generally interested in identifying vulnerability or protective factors that might modify the negative effects of adverse life circumstances (e.g., high subjective perception of stress) on health and well-being (cp. Masten, 2001). A protective factor is defined as something that moderates the effects of risk in a positive direction, whereas a vulnerability factor contributes to an exacerbation of the negative effects of risk. Resilience researchers assume that there are interindividual differences in protective and vulnerability factors, even though these factors also might be subject to change (and thus become mediators). Thus, in line with this perspective, one of the central objectives of our study is to find out whether the assumed (positive) relationship between stress and burnout symptoms is less pronounced among participants with higher levels of PNS compared to participants who report low PNS. To this end, we will test the three-way interaction between perceived stress, LTPA, and PNS on burnout symptoms.

Four hypotheses were tested. First, we expected moderateto-strong correlations between perceived stress, PNS (negative relationships) and occupational burnout symptoms (positive relationship) (Quested et al., 2011; Hämming et al., 2012; Aldrup et al., 2017). Second, we expected that LTPA would be positively associated with PNS (Wilson et al., 2006), and negatively associated with perceived stress (Stults-Kolehmainen and Sinha, 2014) and burnout symptoms (Jonsdottir et al., 2010). Third, we expected that LTPA and PNS would moderate the relationship between perceived stress and burnout, in the sense that if participants reported low stress levels, the relationship between LTPA or PNS and burnout symptoms would be relatively weak, whereas among participants with high stress levels, those with lower LTPA or PNS would report significantly higher burnout levels compared to participants with higher levels of LTPA and PNS. Our third hypothesis seems justified because the stress-buffering effects of LTPA are well documented (Klaperski, 2017). Similarly, previous studies have shown that variables associated with competence (Gerber et al., 2013a), autonomy

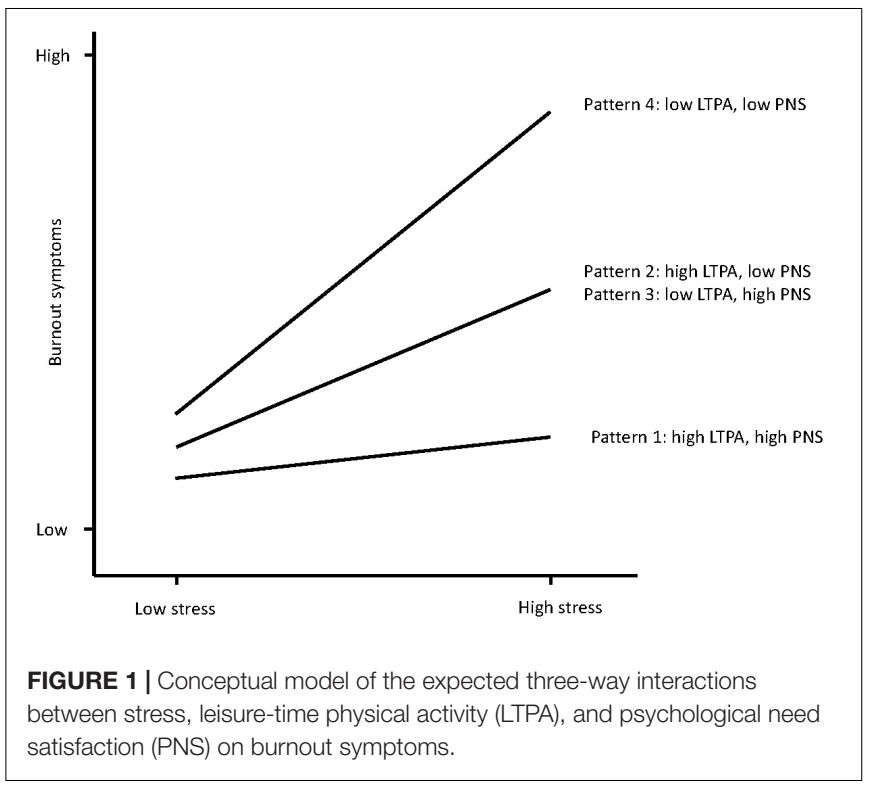

(Bakker et al., 2005), and relatedness (Nakata et al., 2004) have the potential to protect against stress-related health complaints. Fourth, in line with previous research on stress, LTPA and hardiness (Kobasa et al., 1982), we expected that participants with low LTPA and PNS would experience the highest burnout levels if they are faced with stressful life circumstances. A conceptual model that illustrates the expected three-way interaction effects between stress, LTPA and PNS is depicted in Figure $\mathbf{1 .}$

\section{MATERIALS AND METHODS}

\section{Participants and Procedures}

Adult workers were recruited via undergraduate students $(N=87)$ who took part in an introductory course in research methodology at the University of Basel, Switzerland. Students were asked to provide contact details for six to twelve people (not relatives; $18-67$ years old; $\geq 50 \%$ employment) who would be willing to take part in an online survey. Students identified 756 potential participants (46\% women). The study was approved by the local ethics committee, and all participants gave written informed consent. After two reminders, 311 participants (161 men, 150 women; $M_{\text {age }}=42.64$ years, $S D=14.20$ ) filled in an online survey (41\% response rate). All responding participants provided full data. Based on the Mahalanobis distance criterion, none of the participants had to be excluded as a multivariate outlier (based on stress, LTPA, PNS, and burnout scores). However, five participants were excluded as univariate outliers because their self-reported physical activity levels were +3 standard deviations above the mean. Therefore, the final sample $(N=306)$ used in the data analyses consisted of 159 men and 147 women, with a mean age of $M=42.93$ years $(S D=14.12)$. Table 1 provides details regarding the social and demographic background of the sample. 
TABLE 1 | Social and demographic background of the study population.

\begin{tabular}{lccc}
\hline Continuous variables & $\boldsymbol{M}$ & SD & Range \\
\hline Age (in years) & 42.93 & 14.12 & $19-67$ \\
Employment (past & 88.14 & 17.71 & $50-100$ \\
3 months; \% of full & & & \\
employment) & & & \\
Years on job (in years) & 21.82 & 13.94 & $1-47$ \\
Height & 173.37 & 9.16 & $152-195$ \\
Weight & 72.17 & 13.87 & $42-115$ \\
BMl & 23.90 & 3.60 & $17.30-37.20$ \\
\hline
\end{tabular}

\begin{tabular}{|c|c|c|}
\hline Categorical variables & $n$ & $\%$ \\
\hline \multicolumn{3}{|l|}{ Sex } \\
\hline Women & 147 & 48 \\
\hline Men & 159 & 52 \\
\hline \multicolumn{3}{|l|}{ Marital status } \\
\hline Single & 72 & 24 \\
\hline In a relationship & 234 & 76 \\
\hline \multicolumn{3}{|l|}{ Children living at home } \\
\hline Yes & 125 & 41 \\
\hline No & 181 & 59 \\
\hline \multicolumn{3}{|l|}{$\begin{array}{l}\text { Responsibility as a } \\
\text { caregiver }\end{array}$} \\
\hline Yes & 6 & 2 \\
\hline No & 300 & 98 \\
\hline \multicolumn{3}{|l|}{ Nocturnal shift work } \\
\hline Yes & 26 & 8 \\
\hline No & 280 & 92 \\
\hline \multicolumn{3}{|l|}{$\begin{array}{l}\text { Highest completed } \\
\text { education }\end{array}$} \\
\hline Compulsory schooling & 1 & 0 \\
\hline $\begin{array}{l}\text { Vocational education and } \\
\text { training }\end{array}$ & 89 & 29 \\
\hline $\begin{array}{l}\text { Commercial education or } \\
\text { intermediate diploma } \\
\text { school }\end{array}$ & 40 & 13 \\
\hline High school & 28 & 9 \\
\hline $\begin{array}{l}\text { University or university of } \\
\text { applied sciences }\end{array}$ & 148 & 48 \\
\hline \multicolumn{3}{|l|}{ Smoking } \\
\hline Yes & 45 & 15 \\
\hline No & 261 & 85 \\
\hline \multicolumn{3}{|l|}{$\begin{array}{l}\text { Use of psychotropic } \\
\text { medication }\end{array}$} \\
\hline Yes & 4 & 1 \\
\hline No & 302 & 99 \\
\hline
\end{tabular}

\section{Measures}

\section{Perceived Stress}

We used the German version (Klein et al., 2016) of the 4-item shortest version of the Perceived Stress Scale (PSS) (Cohen et al., 1983) to assess general perceived stress during the past month. The items measure the frequency with which respondents find their lives unpredictable, uncontrollable, and overwhelming (e.g., "How often have you felt that you could not control the important things in your life?"). A 5-point Likert scale ranging from 1 (never) to 5 (very often) is used as a response format. Items were summed to obtain an overall score. Validity and reliability of this instrument has been supported previously. While several studies reported acceptable psychometric properties of the PSS-4 (Cohen and Williamson, 1988; Leung et al., 2010), we acknowledged that the internal consistency and model fit was below recommended levels in some studies (Ingram et al., 2016). In the present sample, a confirmatory factor analysis showed that a 1-factor model achieved acceptable model fit, and that factor loadings were adequate (all loadings $\geq 0.45$ ) (Supplementary Figure S1). Moreover, the Cronbach's alpha was satisfactory $(\alpha=0.75)$ in the present sample. Finally, previous studies showed that the associations of the PSS-4 with other stress- and health-related data were comparable with those of the PSS-14 and PSS-10 (Cohen and Williamson, 1988; Leung et al., 2010).

\section{Leisure-Time Physical Activity}

LTPA was measured with a German version (Mäder et al., 2006) of the short form of the International Physical Activity Questionnaire (IPAQ-SF) (Craig et al., 2003). A total index was built based on time spent in MPA (e.g., bicycling at a regular pace and low-intensity sports such as doubles tennis), and VPA (e.g., aerobics and fast bicycling), during the last week, using a frequency-by-duration format. Participants first indicated how many days per week they engaged in these activities (07 days), and then (if applicable) reported the average duration (in minutes). By multiplying frequency and duration scores, we obtained two weekly MPA and VPA estimates. Summing up these scores resulted in a total MVPA index. Adequate validity of the IPAQ has been reported previously (Craig et al., 2003).

\section{Psychological Need Satisfaction}

Satisfaction of the three core psychological needs was measured with the General Need Satisfaction Scale (GNSS) (Gagné, 2003). This instrument consists of 21 items which assess the extent to which the psychological needs of autonomy ( 7 items, e.g., "I feel like I can decide for myself how to live my life."), competence (8 items, e.g., "I often do not feel very capable."), and relatedness (6 items, e.g., "I really like the people I interact with.") are satisfied. Three subscale scores were calculated by building the mean scores. Additionally, the three subscale scores were averaged to obtain a general PNS index. Because the GNSS subscales are highly correlated, we will only use the overall index when calculating two- and three-way interactions (Gagné, 2003; Vansteenkiste et al., 2007). However, descriptive statistics and bivariate correlations are reported for the overall PNS index and the subscales. Since this instrument was not available in German, we used a forward-backward translation procedure to create a German version of the GNSS, following the recommendations of Brislin (1986) (for German items see Supplementary Table S1). Evidence of the factorial validity is provided in the Supplementary Figure S2. As can be seen, the empirical data fitted adequately with the theoretical model. While the three latent factors were highly correlated with each other, all items loaded well on the expected factor (with one exception, all factor loadings $\geq 0.40$ ). Cronbach's alphas for the three subscales varied between 0.71 and 0.75 , the Cronbach's alpha for the overall PNS index was 0.86 . 


\section{Occupational Burnout Symptoms}

A German version (Gerber et al., 2018) of the 14-item ShiromMelamed Burnout Measure (SMBM) (Melamed et al., 1999) was used to assess burnout symptoms. This instrument includes three subscales: (a) physical fatigue (e.g. "I feel physically exhausted."), (b) emotional exhaustion (e.g., "I feel fed-up."), and (c) cognitive weariness. Answers are given on a 7-point Likert scale, with response options ranging from 1 (almost never) to 7 (almost always). An overall SMBM index is derived by calculating the mean across all 14 items, with higher scores reflecting higher burnout symptoms. Sassi and Neveu (2010) showed that the SMBM has good psychometric properties, whereas LundgrenNilsson et al. (2012) found out that scores of $\geq 4.40$ can be considered as clinically relevant. Similar to previous studies (Gerber et al., 2013b; Lindwall et al., 2014), the main analyses were only calculated for the overall burnout SMBM index to avoid the risk of alpha error inflation.

\section{Confounders}

The following social and demographic background variables were assessed as potential confounders, based on participants' selfreports: age (in years), employment rate across the past 3 months (in \% of full employment), years on job (in years), height (in $\mathrm{m}$ ), weight (in $\mathrm{kg})$, sex $(0=$ female, $1=$ male), relationship status $(0=$ single, $1=$ in a relationship $)$, children at home $(0=$ no, $1=$ yes), social responsibility toward relatives in need of care ( $0=$ no responsibility, $1=$ responsibility), nocturnal shift work $(0=$ no, $1=$ yes $)$, highest completed education, smoking $(0=$ no, $1=$ yes $)$, and use of psychotropic medication ( $0=$ no, $1=$ yes $)$. Participants' body mass index (BMI) was calculated with the following formula: $\mathrm{kg} / \mathrm{m}^{2}$.

\section{Statistical Analyses}

First, descriptive statistics ( $M, S D$, range, skewness, and kurtosis) were calculated to describe the main study variables. Second, a series of analyses of variance (ANOVAs) and Pearson product moment correlations were calculated to find out whether participants' burnout levels were associated with the potential confounders. Third, Pearson moment correlations were run to test bivariate relationships between the predictor (stress), moderator (LTPA and PNS) and outcome variables (burnout). Fourth, a $\chi^{2}$-test was performed to find out whether participants who met recommended LTPA levels were less likely to report clinically relevant burnout symptoms. Fifth, a hierarchical (five-stage) regression analysis was calculated to examine whether stress, LTPA, and PNS interacted in predicting burnout symptoms. In the first step, we controlled all potential confounders. In the second step, the main effect of stress was tested, followed by the examination of the main effects for LTPA and PNS in the third step. In the fourth step, all possible twoway interactions (stress*LTPA, stress*PNS, and LTPA*PNS) were controlled. In the fifth step, the three-way interaction between stress, LTPA and PNS (stress*LTPA*PNS) was entered in the regression equation. All variables were $\mathrm{z}$-standardized before the interaction terms were calculated. Moreover, as recommended by Dawson and Richter (2006), we used z-standardized values when performing the hierarchical regression analysis. The following statistical coefficients are provided in the results section: (i) the multiple correlation coefficient squared $R^{2}$ and $F$ value for the total model after step 5, (ii) the stepwise changes in $R^{2}$ and $F$, and (iii) the standardized $(\beta)$, unstandardized regression weights $(B)$ and standard errors (S.E.) for each predictor variable (for the final model). In order to check for multicollinearity, variation inflation factor (VIF) was calculated. VIF scores ranged between 1 and 1.5 for all predictors, and were thus below critical levels (Kutner et al., 2004). Combined with the fact that all correlations between the predictor and moderator variables were below $r=0.50$ (Donath et al., 2012), multicollinearity did not seem to be an issue in the present study. Significant two- and three-way interactions were plotted to facilitate interpretation of the results. To interpret the two- and three-way interactions, the results of the regression analysis plotted with high scores corresponding to values $+1 S D$ and low scores to values $-1 S D^{1}$. Moreover, for the three-way interactions, a simple slope analysis was performed to empirically test, which of the six possible pairs of slopes differ from each other (Dawson and Richter, 2006). The alpha probability level was set at $p<0.05$ across all analyses. All analyses were calculated with SPSS ${ }^{\circledR}$ (version 24, IBM Corporation, Armonk, NY, United States) for Apple Mac ${ }^{\circledR}$.

\section{RESULTS}

\section{Descriptive Statistics}

Table 2 displays the descriptive statistics for all study variables. In the present sample, 18 participants (5.9\%) reported clinically relevant burnout symptoms (SMBM scores $\geq 4.40$ ), whereas 99 participants $(32.4 \%)$ did not attain LTPA recommendations ${ }^{2}$, due to insufficient amounts of VPA ( $<75 \mathrm{~min} /$ week) and/or MVPA (<150 $\mathrm{min} /$ week).

\section{Socio-Demographic Background and Burnout Symptoms}

Significant findings for burnout symptoms were as follows: Participants living in a relationship $(M=2.31, S D=0.95)$ reported lower burnout scores, $F(1,305)=12.11, p=0.001$, $\eta^{2}=0.038$, than singles $(M=2.78, S D=1.10)$, whereas participants with children $(M=2.26, S D=0.93)$ had lower burnout scores than those without children $(M=2.53, S D=1.05)$, $F(1,305)=5.52, p=0.019, \eta^{2}=0.018$. Moreover, those participants who take psychotropic medications reported higher burnout symptoms $(M=4.03, S D=0.85)$ than participants who do not $(M=2.39$, $S D=0.99), F(1,305)=13.44, p=0.001$, $\eta^{2}=0.042$. Finally, age, $r=-0.27, p<0.001$, and years on job, $r=-0.27, p<0.001$, were negatively correlated with self-reported burnout symptoms, highlighting that older and professionally more experienced participants reported lower burnout scores. Nevertheless, age and years on job were highly correlated with each other, $r=0.95, p<0.001$, and therefore we only used age as a covariate in the hierarchical regression analyses. No significant associations were found for

\footnotetext{
${ }^{1}$ http://www.jeremydawson.co.uk/slopes.htm

${ }^{2}$ www.cdc.gov/physicalactivity/basics/index.htm
} 
TABLE 2 | Descriptive statistics and psychometric properties of the major study variables.

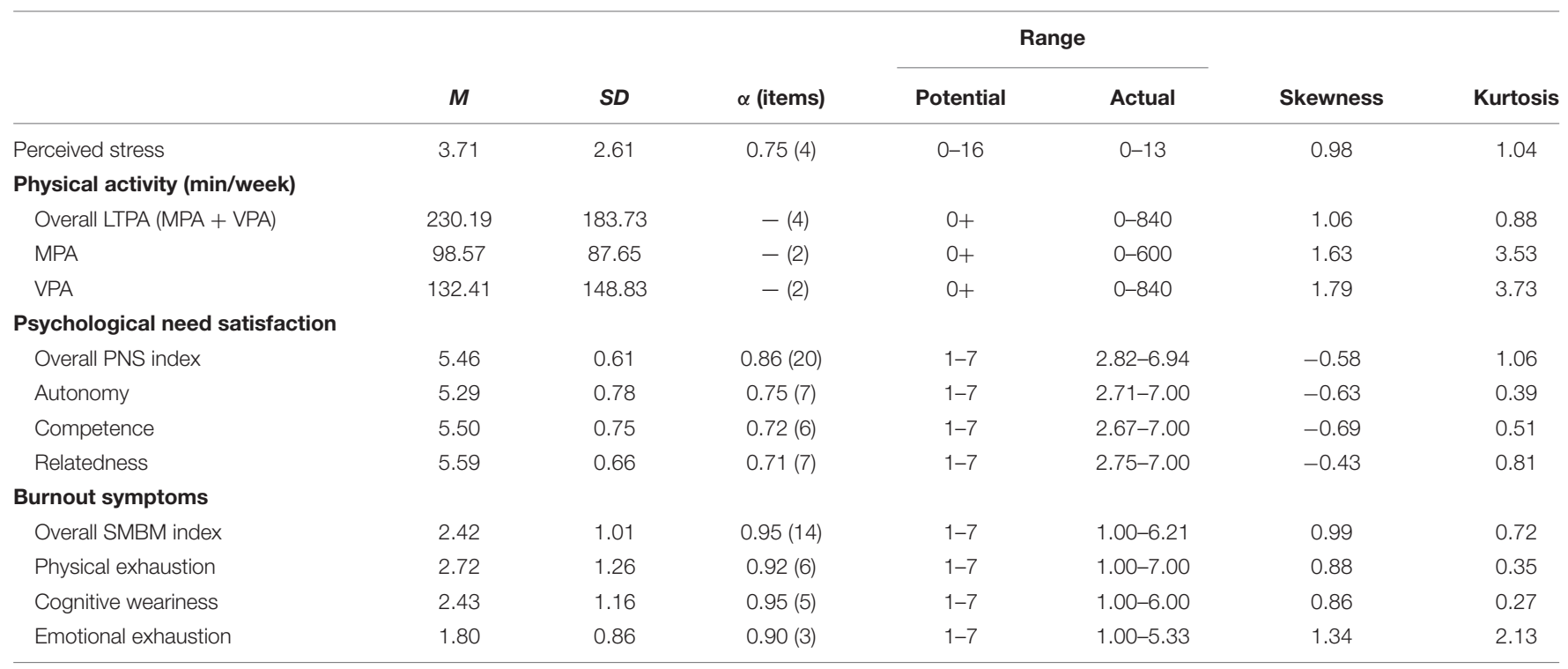

LTPA, leisure-time physical activity; MPA, moderate physical activity; VPA, vigorous physical activity; PNS, psychological need satisfaction; SMBM, Shirom-Melamed Burnout Measure.

TABLE 3 | Summary of inter-correlations for cores on the main study variables.

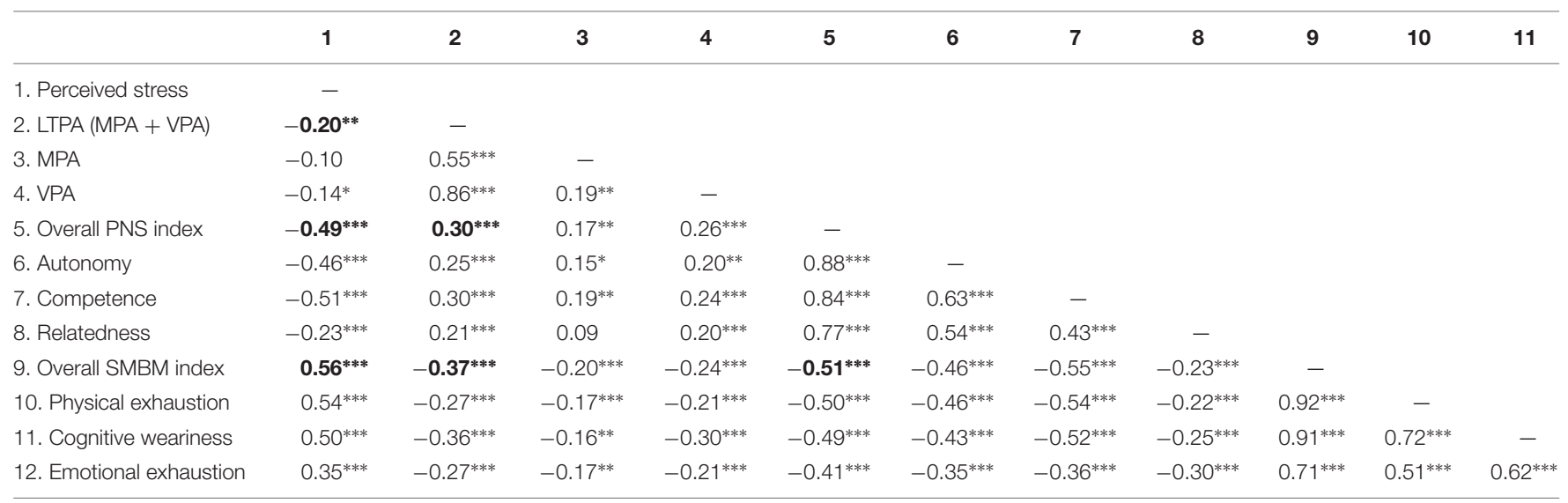

LTPA, leisure-time physical activity; MPA, moderate physical activity; VPA, vigorous physical activity; PNS, psychological need satisfaction; SMBM, Shirom-Melamed Burnout Measure; correlations between overall indices are highlighted in bold. ${ }^{*} p<0.05 ;{ }^{* *} p<0.01$; *** $p<0.001$.

the following variables: sex, $F(1,305)=0.23, p=0.635$, education, $F(4,305)=0.80, p=0.526$, employment, $F(5,305)=0.95$, $p=0.447$, caregiving, $F(1,305)=0.87, p=0.350$, nocturnal shift work, $F(1,305)=0.55, p=0.460$, smoking, $F(1,305)=0.23$, $p=0.631$, height, $r=0.045, p=0.431$, weight, $r=0.00, p=0.961$, and BMI, $r=-0.03, p=0.565$.

\section{Bivariate Associations Between the Main Study Variables}

As shown in Table 3, higher stress levels were strongly associated with more overall burnout symptoms $(r=0.56, p<0.001)$. Participants with higher PNS reported lower stress perceptions $(r=-0.49, p<0.001)$ and fewer burnout symptoms $(r=-0.51$, $p<0.001)$. Similarly, participants with higher LTPA perceived less stress $(r=-0.20, p=0.001)$, indicated higher PNS $(r=0.30$, $p<0.001)$, and reported fewer burnout symptoms $(r=-0.37$, $p<0.001)$.

A $\chi^{2}$-test showed that among those participants with clinically relevant burnout symptoms $(\mathrm{SMBM} \geq 4.40)$, only $22 \%(n=4)$ accomplished recommended LTPA levels. This percentage was considerably higher in the group with SMBM scores below the 4.40 threshold $(71 \%, n=203)$. Thus, participants with insufficient LTPA levels were statistically overrepresented in the group with clinically relevant burnout levels, $\chi^{2}(1,306)=18.03, p<0.001$, $\phi=0.236$.

\section{Physical Activity as a Moderator of the Stress-Burnout Relationship}

Table 4 contains the results of the hierarchical regression analysis. The overall model explained more than half $(57.5 \%)$ of the 
TABLE 4 | Hierarchical multiple regression analyses predicting burnout symptoms with age, relationship status, use of psychotropic medication, perceived stress, leisure-time physical activity and psychological need satisfaction.

\begin{tabular}{|c|c|c|c|c|}
\hline & $\Delta R^{2}$ & $\Delta \mathbf{F}$ & $\beta$ & SE \\
\hline Step 1 & 0.130 & $4.40^{* * *}$ & & \\
\hline Age & & & $-0.22^{* * *}$ & 0.05 \\
\hline Employment rate & & & $0.10^{*}$ & 0.04 \\
\hline Marital status & & & 0.00 & 0.05 \\
\hline $\mathrm{BMl}$ & & & 0.03 & 0.04 \\
\hline Relationship status & & & -0.04 & 0.04 \\
\hline Children at home & & & 0.01 & 0.05 \\
\hline Social responsibility toward relatives & & & 0.01 & 0.04 \\
\hline Nocturnal shift work & & & $0.09 *$ & 0.04 \\
\hline Highest completed education & & & 0.04 & 0.04 \\
\hline Smoking & & & -0.03 & 0.04 \\
\hline Use of psychotropic medication & & & -0.05 & 0.05 \\
\hline Step 2 & 0.251 & $119.07^{* * *}$ & & \\
\hline Stress & & & $0.30^{* * *}$ & 0.05 \\
\hline Step 3 & 0.145 & $44.79^{* * *}$ & & \\
\hline LTPA & & & $-0.21^{* * *}$ & 0.04 \\
\hline PNS & & & $-0.33^{* * *}$ & 0.05 \\
\hline Step 4 & 0.042 & $9.41^{* * *}$ & & \\
\hline Stress $\times$ LTPA & & & $-0.12^{* *}$ & 0.05 \\
\hline Stress $\times$ PNS & & & $0.10^{*}$ & 0.03 \\
\hline LTPA $\times$ PNS & & & $0.11^{*}$ & 0.05 \\
\hline Step 5 & 0.007 & $4.95^{*}$ & & \\
\hline Stress $\times$ LTPA $\times$ PNS & & & $0.10^{*}$ & 0.04 \\
\hline Total $R^{2}$ & 0.575 & & & \\
\hline Total $F$ & $311.56^{* * *}$ & & & \\
\hline Constant & 2.40 & & & \\
\hline
\end{tabular}

LTPA, leisure-time physical activity; PNS, psychological need satisfaction; regression weights are presented as they are after Step 5. ${ }^{* * *} p<0.001$; ${ }^{* *} p<0.01 ; * p<0.05$.

variance in participants' burnout symptoms. More specifically, in the first step, confounders explained $13.0 \%$ of variance, indicating that older participants, those living in a relationship and those not taking psychotropic medication reported fewer burnout symptoms. In the second step, perceived stress explained an additional $25.1 \%$ of variance in burnout $(\beta=0.30, p<0.001)$, showing that higher stress is associated with more burnout symptoms. In the third step, higher LTPA $(\beta=-0.21, p<0.001)$ and PNS levels $(\beta=-0.33, p<0.001)$ were associated with fewer burnout symptoms (explaining $14.5 \%$ of additional variance). In the fourth step, the regression analysis yielded three significant two-way interactions between stress and LTPA $(\beta=-0.12$, $p=0.016)$, stress and PNS $(\beta=0.10, p=0.029)$, and LTPA and PNS $(\beta=0.11, p=0.020)$, explaining a further $4.2 \%$ of variance in burnout symptoms. Figure 2 provides insights regarding the direction of the two-way relationships. Thus, only small differences were found between participants with low vs. high LTPA if stress perceptions were low (Figure 2A) (note that in the plotted regression analyses, low vs. high values are defined as one standard deviation below versus above the mean). Nevertheless, when participants rated their lives as being stressful, a gap opened up, showing that participants with low LTPA report more burnout symptoms than participants with high LTPA. With regard to the interaction between stress and PNS (Figure 2B), the interaction pointed in a different direction. Thus, differences in burnout between participants with low vs. high PNS were bigger when participants reported low stress levels. The two-way interaction between LTPA and PNS reveals that participants with low LTPA and PNS levels report significantly more burnout than participants with low LTPA and high PNS (Figure 2C). Finally, in the fifth step, the threeway interaction between stress, LTPA and PNS explained 0.7\% of variance in burnout symptoms $(\beta=0.10, p=0.027)$. The most important finding of the plotted interaction (Figure 3 ) is that if the level of perceived stress is high, participants with low PNS and low LTPA report significantly higher burnout symptoms than all other participants. The simple slope tests further showed that three pairs of slopes significantly differed from each other (see Table 5). More specifically, the slope of those participants with high MVPA and low PNS levels (flat slope) differed from participants with (a) low MVPA/high PNS and (b) high MVPA/high PNS, in the sense that the latter two groups reported lower burnout levels if stress levels were low, whereas they exhibited similar burnout scores when stress levels were high. In contrast, participants with high MVPA and low PNS levels differed from their counterparts with low MVPA and low PNS, in the sense that the latter group had similar burnout symptoms if stress perceptions were low, whereas they had higher scores if they reported high stress levels.

\section{DISCUSSION}

The purpose of the present study was to examine the threeway interaction between perceived stress, LTPA, and PNS on occupational burnout symptoms. The key finding of the present study is that if adult workers experience high levels of stress, they are particularly likely to show increased burnout levels if they report low LTPA in combination with low PNS, defined as a lack of autonomy, competence and relatedness.

The present study adds to the current literature, as we examined for the first time whether the potential of LTPA to buffer stress-related health complaints depends on whether participants feel their basic psychological needs are (more or less) satisfied. The intention of this study was to explore new territory and give traditional stress-buffer research new impetus by linking LTPA with one of the most popular theories to explain human motivation and development. Thus, grounded in SDT (Ryan and Deci, 2000; Deci and Ryan, 2002), we were able to identify a specific target group for health interventions: individuals who combine low LTPA with low PNS.

In the present study, four hypotheses were tested. First, based on existing research (Quested et al., 2011; Hämming et al., 2012), we expected that stress would be moderately to strongly associated with low PNS and high burnout scores. This hypothesis was supported. Whereas stress is by definition seen as a key factor in the development, maintenance and 


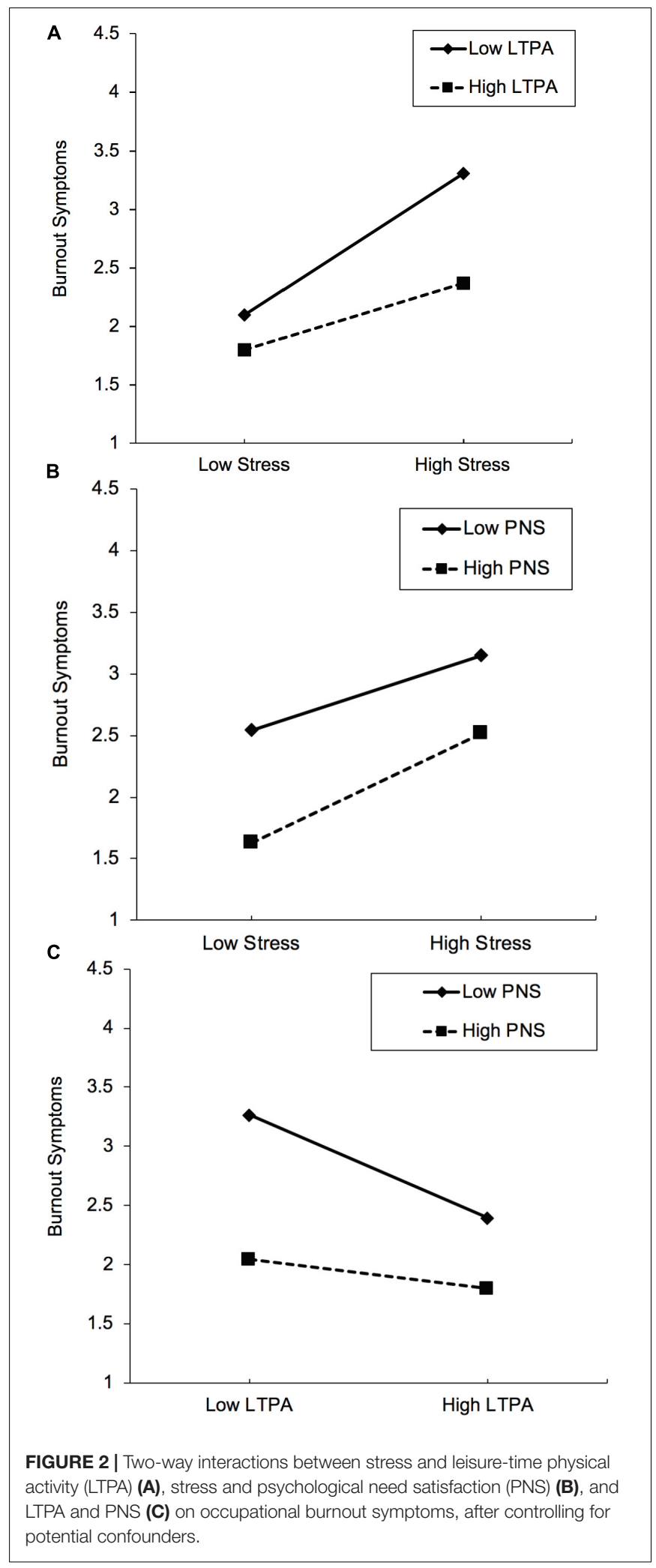

exacerbation of burnout symptoms (Glise et al., 2010), SDT emphasizes that PNS greatly depends on the social context (Ryan and Deci, 2000). Thus, Vansteenkiste and Ryan (2013)

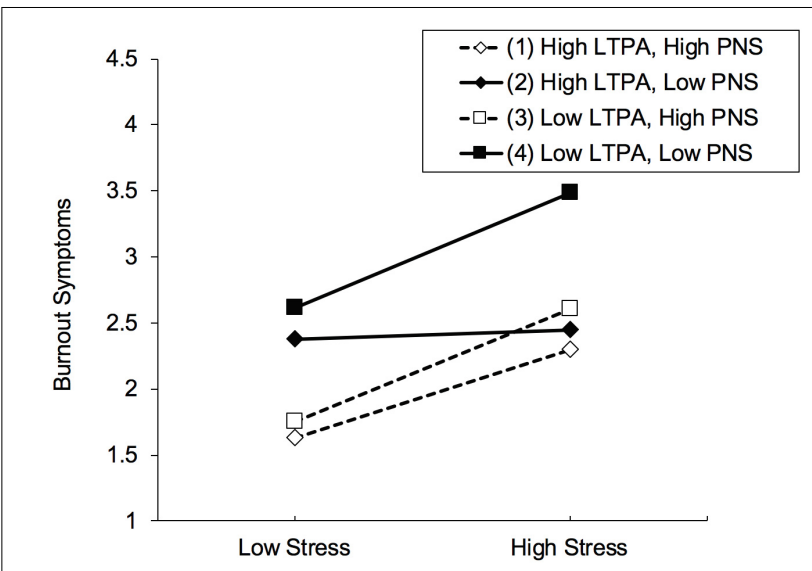

FIGURE 3 | Three-way interaction between stress, leisure-time physical activity (LTPA), and psychological need satisfaction (PNS) on burnout symptoms, after controlling for potential confounders.

TABLE 5 | Slope difference test, comparing slopes depicted in Figure $\mathbf{3}$.

\begin{tabular}{lcc}
\hline Pair of slopes & $\begin{array}{c}\boldsymbol{t} \text {-value for slope } \\
\text { difference }\end{array}$ & $\begin{array}{c}\boldsymbol{p} \text {-value for slope } \\
\text { difference }\end{array}$ \\
\hline $1=$ high LTPA, high PNS & & \\
2 = high LTPA, low PNS & & \\
$3=$ low LTPA, high PNS & & \\
$4=$ low LTPA, low PNS & 3.30 & 0.001 \\
(1) and (2) & -0.71 & 0.481 \\
(1) and (3) & -0.98 & 0.326 \\
(1) and (4) & -3.07 & 0.002 \\
(2) and (3) & -3.70 & 0.000 \\
(2) and (4) & -0.09 & 0.928 \\
(3) and (4) & & \\
\hline
\end{tabular}

argued that "whereas the satisfaction of the psychological needs for autonomy, competence, and relatedness contributes to proactivity, integration, and well-being, the frustration of these same psychological needs leaves one prone to passivity, fragmentation, and ill-being" (p. 263). In line with this notion, it is known from the literature that PNS mediates the relationship between self-perceived stress and burnout symptoms (Van den Broeck et al., 2008; Aldrup et al., 2017). The findings of our study show that measures on all levels (structural, social, and personal) seem worthwhile to reduce the volume of workers' stress and their capacities to deal with challenging situations. Examples of such measures include family-friendly work environments (Secret and Sprang, 2002), creation of an autonomy-supportive climate at work (Havermans et al., 2017), or the promotion of workers' stress management skills, e.g., via mindfulness-based approaches (de Vibe et al., 2012).

Our second hypothesis was that participants with higher LTPA would report elevated PNS. This hypothesis was supported, which corroborates previous investigations showing that LTPA can impact on participants' well-being via increased PNS (Wilson et al., 2006; Gunnell et al., 2011). The findings of our study 
add to the current literature by showing that physically active participants generally see themselves as more autonomous, competent and socially involved. However, we acknowledge that our cross-sectional data cannot be interpreted causally. In other words, it cannot be ruled out that participants with lower PNS are just less motivated to engage in LTPA. Nevertheless, our study expands prior research in an important way, showing that LTPA is associated with general (domainunspecific) PNS, whereas in sport and exercise psychology, researchers generally examined sport-specific PNS as predictor of sport and exercise behavior (Teixeira et al., 2012). Finally, our study points toward the potential of initiatives designed toward fostering physically active lifestyles among employees (Conn et al., 2009), not only to prevent chronic diseases (Kohl and Murray, 2012), but also to promote wellbeing and resilience resources (Gerber et al., 2012; Zayed et al., 2018).

Our third hypothesis was that LTPA and PNS would function as moderators of the stress-burnout relationship. In accordance with this assumption, we found that among participants with elevated stress levels, those with low LTPA reported significantly more burnout symptoms than those with high LTPA. This finding supports the potential of LTPA to buffer stress, which has been well documented in the extant literature (Klaperski, 2017). Both psychological, physiological and behavioral mechanisms have been suggested to explain why LTPA can moderate the relationship between stress and mental health, including differences in cognitive styles (Gerber et al., 2013a), sleep (Gerber et al., 2014a), health-related behaviors (Holmes, 2017), stress-reactivity (Hamer, 2012; Gerber et al., 2017), and cardiometabolic risk factors (Gerber et al., 2016). Furthermore, some researchers have argued that exercise and sport activities have the potential to facilitate recovery from stressful experiences (Sonnentag and Jelden, 2009). This is important because an efficient recovery has been identified as a relevant resilience factor in the work context (Sonnentag and Fritz, 2015). From a practical point of view and a burnoutprevention perspective, we may cautiously infer from our crosssectional findings that regular physical activity is especially important/beneficial if a person is exposed to high stress levels (Naczenski et al., 2017). However, stress and a lack of time have been identified as central physical activity barriers (Stults-Kolehmainen and Sinha, 2014). Therefore, workplace physical activity programs should not only target physical activity behavior, but also behavioral skills that facilitate the implementation of sustainable behavior change (Michie et al., 2011; Nigg, 2013).

Our fourth hypothesis was also supported as stress, LTPA and PNS significantly interacted in the prediction of burnout symptoms. Among participants with high stress levels, those with low LTPA and PNS reported higher burnout levels than those with either high LTPA or high PNS. This finding is in line with previous research on hardiness (Kobasa et al., 1982, 1985), showing that individuals who lack resources across several domains (e.g., low LTPA levels in combination with low PNS) report lower well-being if they are exposed to stressful life circumstances. Conversely, if people perceive low stress levels, having high PNS may compensate for a lack of LTPA, especially in light of the fact that burnout levels were quite high in those with high LTPA and low PNS. Nevertheless, compared to previous studies on hardiness (Kobasa et al., 1982, 1985), no additive effect was found. Thus, if exposed to high stress, participants with high LTPA and high PNS levels reported similarly strong occupational burnout symptoms as counterparts who scored high in only one of these resources. Thus, our findings rather support a compensatory than an additive model. Taken together, we can state that among people with high stress levels, a lack of LTPA and PNS is associated with markedly higher burnout symptoms. Beyond that, our findings do not reveal whether LTPA or PNS should be considered as a more relevant health resource. Thus, when stress levels are low, having high PNS seems to be associated with lower burnout scores, independent of participants' LTPA levels. However, when stress levels are high, a lack of LTPA in combination with low PNS seems to increase the risk of reporting higher burnout symptoms. Given this pattern of results, we can infer that fostering both resources (LTPA and PNS) is worthwhile, but their associations with wellbeing might depend on participants' stress levels.

In order to avoid an overgeneralization of our findings, the following limitations should be considered regarding their interpretation. First, educational background was relatively high in the present study, which limits the generalizability of the data to groups with lower socio-economic status and from lower-status professions. Second, although comparable to other studies among Swiss workers (Gerber et al., 2010), only 40\% of all invited participants completed the questionnaire. Third, the percentage of participants with clinically relevant burnout levels was lower than in previous studies (Gerber et al., 2014b), most likely due to the fact that students tended to approach more healthy individuals and those healthy individuals were more likely to complete the online survey. Fourth, the cross-sectional nature of this study does not allow a causal interpretation of both main and interaction effects. Fifth, interaction effects were only calculated for the composite PNS score. As highlighted by Quested et al. (2011) "this accounts for the tendency of the three needs to have shared variance, but precludes the possibility of determining the independent contribution of each need as a unique predictor of the outcome variables" (p. 832). Sixth, no information was available about the specific occupations participants were from (and response rates within each profession). However, we considered educational background when performing the regression analyses to account for the fact that differences might exist between white versus blue collar workers in their stress, LTPA, PNS and burnout symptoms. Seventh, the lack of objective measurement of LTPA is another limitation that should be addressed in future investigations. This is particularly true as researchers have expressed concerns about the validity of the IPAQ (Lee et al., 2011), because correlations between the IPAQ-SF and accelerometer data were of limited magnitude, and because the IPAQ-SF was associated with an overestimation of physical activity. Nevertheless, in a previous study with Swiss adults, the IPAQ-SF correlated reasonably well with accelerometer data $(r=0.43-0.50)$ 
(Mäder et al., 2006). Moreover, the IPAQ-SF was used successfully with Swiss adolescents to associate physical activity with burnout symptoms (Gerber et al., 2015). Finally, although estimation of physical activity via the IPAQ-SF might entail a certain measurement error, we were able to identify the expected relationships between physical activity and perceived stress $(r=-0.20, p<0.05)$, PNS $(r=0.30, p<0.001)$ and burnout $(r=-0.37, p<0.001)$. Eighth, another direction for future research would be to examine how stress and PNS in different life domains, affect the relationships with occupational burnout. For example, does general PNS buffer work-related stress more than life related stress? Or are buffering effects stronger when needs are supported in the specific context in which there is a high source of stress (e.g., work stress + work PNS). Ninth, burnout is still not considered to be a distinct diagnosis in the ICD-10 (International Classification of Diseases) or DSM5 (Diagnostic and Statistical Manual of Mental Disorders) classification systems. Thus, it would be interesting to know whether the observed moderation effects also occur for other mental health outcomes such as depressive symptoms. However, scholars are currently debating whether and to what degree burnout and depression can be considered as distinct constructs (Bianchi et al., 2015; Schonfeld and Bianchi, 2016). Tenth, we did not estimate sample size from previous studies examining the stress-buffer hypothesis. However, a post hoc power analysis showed that the final sample $(N=306)$ was large enough to detect (significant) bivariate correlations of $r \geq 0.14$ (using $G^{*}$ Power 3.1, point biserial model, one-tailed, $\alpha$ error probability $=0.05$, Power $=0.80$ ) between the study variables. Accordingly, our study was sufficiently powered to identify even small (main) effects of the predictor variables on the outcome. However, as scholars have highlighted previously (McClelland and Judd, 1993), detecting interaction effects with observational data is difficult because the interaction term is considered only after having accounted for the main effects (leaving limited variance to explain). Finally, the SMBM which was used in this study is not the same measure as SMBQ which was used in the LundgrenNilsson et al. (2012) paper which we referred to for clinical cut-offs. Although the items are similar, the cut-offs need to be interpreted with caution. Nevertheless, the $\geq 4.40$ threshold is the only empirically derived cut-off, which we prefer to any arbitrarily set cut-off.

\section{CONCLUSION}

Low levels of LTPA and low PNS were associated with more burnout symptoms and more perceived stress. Most importantly, participants who showed both low LTPA and low PNS when faced with stressful life circumstances reported the most burnout

\section{REFERENCES}

Aldrup, K., Klusmann, U., and Lüdtke, O. (2017). Does basic need satisfaction mediate the link between stress exposure and well-being? A diary study among beginning teachers. Learn. Instr. 50, 21-30. doi: 10.1016/j.learninstruc.2016. 11.005 symptoms. Thus, based on our cross-sectional data, we cautiously conclude that participating in LTPA or feeling that one's psychological needs (autonomy, competence, and relatedness) are satisfied may off-set some of the negative consequences associated with perceived stress, in particular symptoms of burnout. To counteract the burden associated with chronic stress exposure, we encourage the adherence to more physically active lifestyles and the creation of need-supportive climates in the family, in the leisure area, and at work.

\section{AVAILABILITY OF DATA AND MATERIAL}

Can be requested for further analyses or transparency reasons from the corresponding author.

\section{ETHICS STATEMENT}

This study was carried out in accordance with the recommendations of the Federal Act on Research involving Human Beings (Humanforschungsgesetz, HFG) with written informed consent from all subjects. All subjects gave written informed consent in accordance with the Declaration of Helsinki. The protocol was approved by the local ethical committee (EKNZ; Ethical Committee of Northwestern and Central Switzerland).

\section{AUTHOR CONTRIBUTIONS}

MG, SI-G, RS, SL, SB, and FC developed the study design, interpreted the data, revised the manuscript draft internally, and approved the final version of the manuscript. MG coordinated the study and was responsible for the data assessment. MG, SI-G, RS, $\mathrm{SL}, \mathrm{SB}$, and FC contributed to the statistical analyses. MG wrote the manuscript.

\section{ACKNOWLEDGMENTS}

We cordially thank all the patients for their engagement. We also thank Dr. Harald Seelig (University of Basel, Switzerland) for the statistical support during the revision process.

\section{SUPPLEMENTARY MATERIAL}

The Supplementary Material for this article can be found online at: https://www.frontiersin.org/articles/10.3389/fpsyg. 2018.02097/full\#supplementary-material

Baard, P., Deci, E. L., and Ryan, R. M. (2004). Intrinsic need satisfaction: a motivational basis of performance and well-being in two work settings. J. Appl. Soc. Psychol. 34, 2045-2068. doi: 10.1111/j.1559-1816.2004.tb02690.x

Bakker, A. B., Demerouti, E., and Euwema, M. C. (2005). Job resources buffer the impact of job demands on burnout. J. Occup. Health Psychol. 10, 170-180. doi: $10.1037 / 1076-8998.10 .2 .170$ 
Bergmann, N., Gyntelberg, F., and Faber, J. (2014). The appraisal of chronic stress and the development of the metabolic syndrome: a systematic review of prospective cohort studies. Endocr. Connect. 3, R55-R80. doi: 10.1530/EC-140031

Bianchi, R., Schonfeld, I. S., and Laurent, E. (2015). Burnout-depression overlap: a review. Clin. Psychol. Rev. 36, 28-41. doi: 10.1016/j.cpr.2015.01.004

Biddle, S. J., and Mutrie, N. (2006). Psychology of Physical Activity: Determinants, Well-Being and Interventions. London: Routledge.

Bretland, R. J., and Thorsteinsson, E. B. (2015). Reducing workplace burnout: the relative benefits of cardiovascular and resistance exercise. PeerJ 3:e891. doi: $10.7717 /$ peerj.7891

Brislin, R. W. (1986). “The wording and translation of research instrument," in Field Methods in Cross-Cultural Research, eds W. J. Lonner and J. W. Berry (Beverly Hills, CA: Sage), 137-164.

Cohen, S., Kamarck, T., and Mermelstein, R. (1983). A global measure of perceived stress. J. Health Soc. Behav. 24, 385-396. doi: 10.2307/213 6404

Cohen, S., and Williamson, G. M. (1988). "Perceived stress in a probability sample of the united states," in The Social Psychology of Health, eds S. Spacapan and S. Oskamp (Newbury Park, CA: Sage), 31-67.

Conn, V. S., Hafdahl, A. R., Cooper, P. S., Brown, L. M., and Lusk, S. L. (2009). Meta-analysis of workplace physical activity interventions. Am. J. Prev. Med. 37, 330-339. doi: 10.1016/j.amepre.2009.06.008

Craig, C. L., Marshall, A. L., Sjöström, M., Bauman, A. E., Booth, M. L., Ainsworth, B. E., et al. (2003). International physical activity questionnaire: 12-country reliability and validity. Med. Sci. Sports Exerc. 35, 1381-1395. doi: 10.1249/01. MSS.0000078924.61453.FB

Dawson, J. F., and Richter, A. W. (2006). Probing three-way interactions in moderated multiple regression: development and application of a slope difference test. J. Appl. Psychol. 91, 917-926. doi: 10.1037/0021-9010.91. 4.917

de Vibe, M., Bjørndal, A., Tipton, E., Hammerstrøw, K. T., and Kowalski, K. (2012). Mindfulness based stress reduction (MBSR) for improving health, quality of life, and social functioning in adults. Campbell Syst. Rev. 8. doi: 10.4073/csr.2012.3

de Vries, J., Van Hooff, M., Guerts, S., and Kompier, M. (2017). Exercise to reduce work-related fatigue among employees: a randomized controlled trial. Scand. J. Work Environ. Health 43, 337-349. doi: 10.5271/sjweh. 3634

Deci, E. L., and Ryan, R. M. (2000). The 'what' and 'why' of goal pursuits: human needs and the self-determination of behaviour. Psychol. Inq. 11, 319-338. doi: 10.1207/S15327965PLI1104_01

Deci, E. L., and Ryan, R. M. (2002). "Overview of self-determination theory: an organismic dialectical perspective," in Handbook of Self-Determination Research, eds E. L. Deci and R. M. Ryan (Rochester, NY: University of Rochester Press), 3-36.

Donath, C., Grässel, E., Baier, D., Pfeiffer, C., and Bleich, S. (2012). Predictors of binge drinking in adolescents: ultimate and distal factors a representative study. BMC Public Health 12:263. doi: 10.1186/1471-2458$12-263$

Elliot, C., Lang, C., Brand, S., Holsboer-Trachsler, E., Pühse, U., and Gerber, M. (2015). The relationship between meeting vigorous physical activity recommendations and burnout symptoms among adolescents: an exploratory study with vocational students. J. Sport Exerc. Psychol. 37, 180-192. doi: 10. 1123/jsep.2014-0199

Gagné, M. (2003). The role of autonomy support and autonomy orientation in prosocial behavior engagement. Motiv. Emot. 27, 199-233. doi: 10.1023/A: 1025007614869

Gerber, M., Börjesson, M., Ljung, T., Lindwall, M., and Jonsdottir, I. (2016). Fitness moderates the relationship between stress and cardiovascular risk factors. Med. Sci. Sports Exerc. 48, 2075-2081. doi: 10.1249/MSS.00000000000 01005

Gerber, M., Brand, S., Herrmann, C., Colledge, F., Holsboer-Trachsler, E., and Pühse, U. (2014a). Increased objectively assessed vigorous-intensity exercise is associated with reduced stress, increased mental health and good objective and subjective sleep in young adults. Physiol. Behav. 135, 17-24. doi: 10.1016/j. physbeh.2014.05.047

Gerber, M., Jonsdottir, I. H., Lindwall, M., and Ahlborg, G. (2014b). Physical activity in employees with differing occupational stress and mental health profiles: a latent profile analysis. Psychol. Sport Exerc. 15, 649-658. doi: 10.1016/ j.psychsport.2014.07.012

Gerber, M., Colledge, F., Mücke, M., Schilling, R., Brand, S., and Ludyga, S. (2018). Psychometric properties of the Shirom-Melamed Burnout Measure (SMBM) among adolescents: results from three cross-sectional studies. BMC Psychiatry 18:266. doi: 10.1186/s12888-018-1841-5

Gerber, M., Kalak, N., Lemola, S., Clough, P. J., Perry, J. L., Pühse, U., et al. (2013a). Are adolescents with high mental toughness levels more resilient against stress? Stress Health 29, 164-171. doi: 10.1002/smi.2447

Gerber, M., Lindwall, M., Lindegård, A., Börjesson, M., and Jonsdottir, I. H. (2013b). Cardiovascular fitness protects from stress-related symptoms of burnout and depression. Patient Educ. Couns. 93, 146-152. doi: 10.1016/j.pec. 2013.03.021

Gerber, M., Kalak, N., Lemola, S., Clough, P. J., Pühse, U., Elliot, C., et al. (2012). Adolescents' exercise and physical activity are associated with mental toughness. Ment. Health Phys. Act. 5, 35-42. doi: 10.1016/j.mhpa.2012.02.004

Gerber, M., Kellmann, M., Hartmann, T., and Pühse, U. (2010). Do exercise and fitness buffer against stress among Swiss police and emergency response service officers? Psychol. Sport Exerc. 11, 286-294. doi: 10.1016/j.psychsport.2010.02.004

Gerber, M., Lang, C., Feldmeth, A. K., Elliot, C., Brand, S., Hoslboer-Trachsler, E., et al. (2015). Burnout and mental health in Swiss vocational students: the moderating role of physical activity. J. Res. Adolesc. 25, 63-74. doi: 10.1111/ jora. 12097

Gerber, M., Ludyga, S., Mücke, M., Colledge, F., Brand, S., and Pühse, U. (2017). Low vigorous physical activity is associated with increased adrenocortical reactivity to psychosocial stress in students with high stress perceptions. Psychoneuroendocrinology 80, 104-113. doi: 10.1016/j.psyneuen.2017. 03.004

Glise, K., Hadzibajramovic, E., Jonsdottir, I. H., and Ahlborg, G. Jr. (2010). Self-reported exhaustion: a possible indicator of reduced work ability and increased risk of sickness absence among human service workers. Int. Arch. Occup. Environ. Health 83, 511-520. doi: 10.1007/s00420-0090490-x

Grossi, G., Perski, A., Akstedt, M., Johannson, T., Lindström, M., and Holm, K. (2005). The morning salivary cortisol response in burnout. J. Psychosom. Res. 59, 103-111. doi: 10.1016/j.jpsychores.2005.02.009

Gunnell, K. E., Crocker, P. R. E., Wilson, P. M., Mack, D. E., and Zumbo, B. D. (2013). Psychological need satisfaction and thwarting: a test of Basic Psychological Needs Theory in physical activity contexts. Psychol. Sport Exerc. 14, 599-607. doi: 10.1016/j.psychsport.2013.03.007

Gunnell, K. E., Mack, D. E., Wilson, P. M., and Adachi, J. D. (2011). Psychological needs as mediators? The relationship between leisure-time physical activity and wellbeing in people diagnosed with osteoporosis. Res. Q. Exerc. Sport 82, 593-598. doi: 10.1080/02701367.2011.10599817

Hamer, M. (2012). Psychosocial stress and cardiovascular disease risk: the role of physical activity. Psychosom. Med. 74, 896-903. doi: 10.1097/PSY. 0b013e31827457f4

Hämming, O., Brauchli, R., and Bauer, G. F. (2012). Effort-reward and worklife imbalance, general stress and burnout among employees of a large public hospital in Switzerland. Swiss Med. Wkly. 142:w13577. doi: 10.4414/smw.2012. 13577

Havermans, B. M., Boot, C. R., Houtman, I. L., Brouwers, E. P., Anema, J. R., and Van Der Beek, A. J. (2017). The role of autonomy and social support in the relation between psychosocial safety climate and stress in health care workers. BMC Public Health 17:558. doi: 10.1186/s12889-017-4484-4

Hobfoll, S. E., and Shirom, A. (2000). "Conservation of resources theory: applications to stress and management in the workplace," in Handbook of Organization Behavior, ed. R. T. Golembiewski (New York, NY: Dekker), 57-81.

Holmes, M. (2017). "Physical activity, stress and obesity," in Stressregulation und Sport, eds R. Fuchs and M. Gerber (Heidelberg: Springer).

Ilardi, B., Leone, D., Kasser, T., and Ryan, R. M. (1993). Employee and supervisor ratings of motivation: main effects and discrepancies associated with job satisfaction and adjustment in a factory setting. J. Appl. Soc. Psychol. 23, 1789-1805. doi: 10.1111/j.1559-1816.1993.tb01066.x

Ingram, P. B., Clarke, E., and Lichtenberg, J. W. (2016). Confirmatory factor analysis of the perceived stress scale- 4 in a community sample. Stress Health 32, 173-176. doi: 10.1002/smi.2592 
Jonsdottir, I. H., Rödjer, L., Hadzibajramovic, E., Börjesson, M., and Ahlborg, G. J. (2010). A prospective study of leisure-time physical activity and mental health in Swedish health care workers and social insurance officers. Prev. Med. 51, 373-377. doi: 10.1016/j.ypmed.2010.07.019

Klaperski, S. (2017). "Exercise, stress and health: the stress-buffering effect of exercise," in Stressregulation und Sport, eds R. Fuchs and M. Gerber (Heidelberg: Springer), 227-250.

Klein, E. M., Brähler, E., Dreier, M., Reinecke, L., Müller, K. W., Schmutzer, G., et al. (2016). The German version of the Perceived Stress Scale - psychometric characteristics in a representative German community sample. BMC Psychiatry 16:159. doi: 10.1186/s12888-016-0875-9

Kobasa, S. C., Maddi, S. R., and Puccetti, M. C. (1982). Personality and exercise as buffers in the stress-illness-relationship. J. Behav. Med. 5, 391-404. doi: 10.1007/BF00845369

Kobasa, S. C., Maddi, S. R., Puccetti, M. C., and Zola, M. A. (1985). Effectiveness of hardiness, exercise and social support as resources against illness. J. Psychsom. Med. 29, 525-533. doi: 10.1016/0022-3999(85)90086-8

Kohl, H. W. R., and Murray, T. (2012). Foundations of Physical Activity and Public Health. Champaign, IL: Human Kinetics.

Kutner, M., Nachtsheim, C., and Neter, J. (2004). Applied Linear Statistical Models. Irwin, CA: McGraw-Hill.

Lee, P. H., Macfarlane, D. J., Lam, T. H., and Stewart, S. M. (2011). Validity of the international physical activity questionnaire short form (IPAQ-SF): a systematic review. Int. J. Behav. Nutr. Phys. Act. 8:115. doi: 10.1186/1479-5868-1188-1115

Leung, D. Y. P., Lam, T. H., and Chan, S. S. C. (2010). Three versions of Perceived Stress Scale: validation in a sample of Chinese cardiac patients who smoke. BMC Public Health 10:513. doi: 10.1186/1471-2458-10-513

Lindwall, M., Gerber, M., Jonsdottir, I., Börjesson, M., and Ahlborg, G. J. (2014). The relationships of change in physical activity with change in depression, anxiety, and burnout: a longitudinal study of Swedish healthcare workers. Health Psychol. 33, 1309-1318. doi: 10.1037/a0034402

Lindwall, M., Ljung, T., Hadzibajramovic, E., and Jonsdottir, I. (2012). Selfreported physical activity and aerobic fitness are differently related to mental health. Ment. Health Phys. Act. 5, 28-34. doi: 10.1016/j.mhpa.2011.12.003

Lundgren-Nilsson, A., Jonsdottir, I. H., Pallant, J., and Ahlborg, G. (2012). Internal construct validity of the Shirom-Melamed Burnout Questionnaire (SMBQ). BMC Public Health 12:1. doi: 10.1186/1471-2458-12-1

Luthar, S. S., Sawyer, J. A., and Brown, P. J. (2006). Conceptual issues in studies of resilience: past, present, and future research. Ann. N. Y. Acad. Sci. 1094, 105-115. doi: 10.1196/annals.1376.009

Lynch, M., Plant, R., and Ryan, R. M. (2005). Psychological needs and threat to safety: implications for staff and patients in a psychiatric hospital for youth. Prof. Psychol. Res. Pract. 36, 415-425. doi: 10.1037/0735-7028.36.4.415

Mäder, U., Martin, B. W., Schutz, Y., and Marti, B. (2006). Validity of four short physical activity questionnaires in middle-aged persons. Med. Sci. Sports Exerc. 38, 1255-1266. doi: 10.1249/01.mss.0000227310.18902.28

Masten, A. S. (2001). Ordinary magic: resilience processes in development. Am. Psychol. 56, 227-238. doi: 10.1037/0003-066X.56.3.227

McClelland, G. H., and Judd, C. M. (1993). Statistical difficulties of detecting interactions and moderator effects. Psychol. Bull. 114, 376-390. doi: 10.1037/ 0033-2909.114.2.376

Mead, G. E., Morley, D., Campbell, P., Greig, C. A., Mcmurdo, M. E. T., and Lawlor, D. A. (2009). Exercise for depression. Cochrane Database Syst. Rev. 3:CD004366. doi: 10.1002/14651858.CD14004366.pub14651854

Melamed, S., Shirom, A., Toker, S., and Shapira, I. (2006). Burnout and risk of type 2 diabetes: a prospective study of apparently healthy employed persons. Psychsom. Med. 68, 863-869. doi: 10.1097/01.psy.0000242860. 24009.f0

Melamed, S., Ugarten, U., Shirom, A., Kahana, L., Lerman, Y., and Froom, P. (1999). Chronic burnout, somatic arousal and elevated cortisol levels. J. Psychosom. Med. 46, 591-598. doi: 10.1016/S0022-3999(99) 00007-0

Michie, S., Van Stralen, M. M., and West, R. (2011). The behaviour change wheel: a new method for characterising and designing behaviour change interventions. Implement. Sci. 6:42. doi: 10.1186/1748-5908-1186-1142

Milayavskaya, M., and Koestner, R. (2011). Psychological needs, motivation, and well-being: a test of self-determination theory across multiple domains. Pers. Individ. Dif. 50, 387-391. doi: 10.1016/j.paid.2010.10.029
Naczenski, L. M., De Vries, J., Van Hooff, M. L. M., and Kompier, M. A. J. (2017). Systematic review of the association between physical activity and burnout. J. Occup. Health 59, 477-494. doi: 10.1539/joh.15170050-RA

Nakata, A., Haratani, T., Takahashi, M., Kawakami, N., Arito, H., Kobayashi, F., et al. (2004). Job stress, social support, and prevalence of insomnia in a population of Japanese daytime workers. Soc. Sci. Med. 59, 1719-1730. doi: $10.1016 /$ j.socscimed.2004.02.002

Nigg, C. R. (2013). ACSM's Behavioral Aspects of Physical Activity and Exercise. Little Rock, AR: Lippincott Williams \& Wilkins.

Quested, E., Bosch, J. A., Burns, V. E., Cumming, J., Ntoumanis, N., and Duda, J. L. (2011). Basic psychological need satisfaction, stress-related appraisals, and dancers' cortisol and anxiety responses. J. Sport Exerc. Psychol. 33, 828-846. doi: 10.1123/jsep.33.6.828

Redmond, N., Richman, J., Gamboa, C. M., Albert, M. A., Sims, M., Durant, R. W., et al. (2013). Perceived stress is associated with incident coronary heart disease and all-cause mortality in low- but not high-income participants in the Reasons for Geographic and Racial Differences in Stroke study. J. Am. Heart. Assoc. 2:e00447. doi: 10.1161/JAHA.1113.000447

Reis, H. T., Sheldon, K. M., Gable, S. L., Roscoe, J., and Ryan, R. M. (2000). Daily well-being: the role of autonomy, competence, and relatedness. Pers. Soc. Psychol. Bull. 26, 419-435. doi: 10.1177/0146167200266002

Ryan, R. M., and Deci, E. L. (2000). Self-Determination Theory and the facilitation of intrinsic motivation, social development, and well-being. Am. Psychol. 55, 68-78. doi: 10.1037/0003-066X.55.1.68

Sassi, N., and Neveu, J.-P. (2010). Traduction et validation d'une nouvelle mesure d'épuisement professionnel: le Shirom-Melamed Burnout Measure. Can. J. Behav. Sci. 42, 177-184. doi: 10.1037/a0017700

Schaufeli, W. B., and Bakker, A. B. (2004). Job demands, job resources, and their relationship with burnout and engagement: a multi-sample study. J. Organ. Behav. 25, 293-315. doi: 10.1002/job.248

Schonfeld, I. S., and Bianchi, R. (2016). Burnout and depression: two entities or one? J. Clin. Psychol. 72, 22-37. doi: 10.1002/jclp.22229

Secret, M., and Sprang, G. (2002). The effects of family-friendly workplace environments on work-family stress of employed parents. J. Soc. Sci. Res. 28, 21-45. doi: 10.1300/J079v28n02_02

Shirom, A., Melamed, S., Toker, S., Berliner, S., and Shapira, I. (2006). Burnout and health review: current knowledge and future research directions. Int. Rev. Indust. Organ. Psychol. 20, 269-309.

Siegrist, J. (2008). Chronic psychosocial stress at work and risk of depression: evidence from prospective studies. Eur. Arch. Psychiatry Clin. Neurosci. 258, 115-119. doi: 10.1007/s00406-008-5024-0

Sonnentag, S., and Fritz, C. (2015). Recovery from job stress: the stressordetachment model as an integrative framework. J. Organ. Behav. 36, 72-103. doi: $10.1002 /$ job. 1924

Sonnentag, S., and Jelden, S. (2009). Job stressors and the pursuit of sport activities: a day-level perspective. J. Occup. Health Psychol. 14, 165-181. doi: 10.1037/ a0014953

Stults-Kolehmainen, M. A., and Sinha, R. (2014). The effects of stress on physical activity and exercise. Sports Med. 44, 81-121. doi: 10.1007/s40279-0130090-5

Teixeira, P. J., Carraca, E. V., Markland, D., Silva, M. N., and Ryan, R. M. (2012). Exercise, physical activity, and self-determination theory: a systematic review. Int. J. Behav. Nutr. Phys. Act. 9:78. doi: 10.1186/1479-58681189-1178

Toker, S., Shirom, A., Shapira, I., Berliner, S., and Melamed, S. (2005). The association between burnout, depression, anxiety, and inflammation biomarkers: C-reactive protein and fibrinogen in men and women. J. Occup. Health Psychol. 10, 344-362. doi: 10.1037/1076-8998.10. 4.344

Tsai, H., Yeh, C., Su, C., Chen, C., Peng, S., and Chen, R. (2013). The effects of exercise program on burnout and metabolic syndrome components in banking and insurance workers. Indust. Health 51, 336-346. doi: 10.2486/indhealth. 2012-0188

Van den Broeck, A., Vansteenkiste, M., De Witte, H., and Lens, W. (2008). Explaining the relationship between job characteristics, burnout, and engagement: the role of basic psychological need satisfaction. Work Stress 22, 277-294. doi: 10.1080/02678370802393672 
Vansteenkiste, M., Neyrinck, B., Niemic, C., Soenens, B., De Witte, H., and Van den Broeck, A. (2007). Examining the relations among extrinsic versus intrinsic work value orientations, basic need satisfaction, and job experience: a Self-Determination Theory approach. J. Occup. Organ. Health 80 , 251-277.

Vansteenkiste, M., and Ryan, R. M. (2013). On psychological growth and vulnerability: basic psychological need satisfaction and need frustration as a unifying principle. J. Psychother. Integr. 23, 263-280. doi: 10.1037/a003 2359

Wilson, P. M., Longley, K., Muon, S., Rodgers, W. M., and Murray, T. C. (2006). Examining the contributions of perceived need satisfaction to well-being in exercise. J. Appl. Biobehav. Res. 11, 243-264. doi: 10.1111/j.1751-9861.2007. 00008.x

Wunsch, K., and Gerber, M. (2017). "Sportaktivität, stress und burnout," in Stressregulation und Sport, eds R. Fuchs and M. Gerber (Heidelberg: Springer), 343-374.
Zayed, K. N., Ahmed, M. D., Van Niekerk, R. L., and Ho, W. K. (2018). The mediating role of exercise behaviour on satisfaction with life, mental well-being and BMI among university employees. Cogent. Psychol. 5:1430716. doi: $10.1080 / 23311908.23312018 .21430716$

Conflict of Interest Statement: The authors declare that the research was conducted in the absence of any commercial or financial relationships that could be construed as a potential conflict of interest.

Copyright ( 2018 Gerber, Isoard-Gautheur, Schilling, Ludyga, Brand and Colledge. This is an open-access article distributed under the terms of the Creative Commons Attribution License (CC BY). The use, distribution or reproduction in other forums is permitted, provided the original author(s) and the copyright owner(s) are credited and that the original publication in this journal is cited, in accordance with accepted academic practice. No use, distribution or reproduction is permitted which does not comply with these terms. 